Revista Destaques Acadêmicos, Lajeado, v. 11, n. 3, 2019. ISSN 2176-3070

DOI: http://dx.doi.org/10.22410/issn.2176-3070.v11i3a2019.2113

http://www.univates.br/revistas

\title{
O EXERCÍCIO DA PARENTALIDADE SOB O OLHAR DA TERAPIA DO ESQUEMA E OUTRAS CONTRIBUIÇÕES TEÓRICAS
}

\author{
Grazieli Freitas Bordman ${ }^{1}$, Guilherme Costa, Luisa Kraus Mendes, \\ Rutielle Katiane de Paula, Vanessa Cristina Ehrlich, Maikon de Sousa Michels ${ }^{2}$
}

Resumo: Esse artigo teve como objetivo principal compreender, a partir do entrelaçamento de algumas teorias, tais como Terapia do Esquema, Teoria do Apego e o estudo de etnoteorias parentais, o exercício da parentalidade - de que maneira tais compreensões teóricas podem auxiliar o exercício do papel parental para o desenvolvimento saudável da criança. Para tanto, foram entrevistados seis pais, a partir de um roteiro semi-estruturado. Os resultados indicaram a relação entre o exercício parental e a estruturação da personalidade da criança, de forma que a Terapia do Esquema pode auxiliar ao identificar ambientes que não suprem suas necessidades da criança e auxiliar as figuras parentais nesse empreendimento. Sugerimos que novos estudos utilizem a observação na metodologia.

Palavras-chave: Terapia do Esquema; Teoria do Apego, etnoparentalidade.

\section{INTRODUÇÃO}

Em fevereiro de 2017, a Organização Mundial da Saúde - OMS divulgou o relatório "Depression and other common mental disorders: global health estimates", revelando que no Brasil, cerca de $5,8 \%$ da população (11.548.577 pessoas) é atingida pela depressão, e 9,3\% da população (18.657.943 pessoas) é afetada por algum distúrbio de ansiedade. Ou seja, tratando-se de apenas dois transtornos,

1 Acadêmicos do $4^{\circ}$ ano do curso de graduação em Psicologia da Universidade da Região de Joinville - UNIVILLE. Disciplina de Terapia Cognitivo-comportamental.

2 Orientador, professor do curso de Psicologia da Universidade da Região de Joinville UNIVILLE. Possui Mestrado em Patrimônio Cultural e Sociedade pela Universidade da Região de Joinville; Graduação em Psicologia pela Associação Catarinense de Ensino (ACE); Especialização em Neuropsicologia pelo Instituto Paranaense de Terapia Cognitiva (IPTC) e pelo Conselho Regional de Psicologia (CRP 12); Especialização em Psicoterapias Cognitivas pelo Instituto Paranaense de Terapia Cognitiva (Psicologia clínica pelo Conselho Regional de Psicologia) 
há pelo menos 30 milhões de indivíduos acometidos no Brasil. O mesmo relatório indicou um aumento de 18\% nos casos de depressão, entre 2005 e 2015, em todo o mundo.

Diante desse cenário, faz-se necessário investigar estratégias de prevenção ou promoção da saúde mental. Paim e Rosa (2016) tratam do papel preventivo da terapia do esquema já na infância. De acordo com as autoras, a terapia do esquema, desenvolvida por Jeffrey Young, possui grande validade nesse sentido, uma vez que entende a relação entre as vivências na infância e o desenvolvimento de disfunções na vida adulta.

Young, Klosko e Weishaar (2008) indicam a existência de cinco necessidades emocionais fundamentais para os seres humanos: vínculos seguros com outros indivíduos; autonomia, competência e sentido de identidade; liberdade de expressão, validação de necessidades e emoções; espontaneidade e lazer; limites realistas e autocontrole. Para os autores, "um indivíduo psicologicamente saudável é aquele que consegue satisfazer de forma adaptativa as necessidades emocionais fundamentais" (YOUNG; KLOSKO; WEISHAR, 2008, p. 24). Por outro lado, relações primárias que não satisfaçam adequadamente essas necessidades constituem a origem do que é denominado de esquemas iniciais desadaptativos - EIDs.

De acordo com Beck, um dos pioneiros no campo da psicoterapia cognitivo-comportamental, "qualquer princípio organizativo amplo que um indivíduo use para entender a própria experiência de vida pode ser considerado um esquema." (BECK, 1967 apud, YOUNG; KLOSKO; WEISHAR, 2008, p. 22). Ainda, segundo Knapp et al. (2004), esquemas podem ser entendidos como estruturas cognitivas compostas por crenças - conceitos enraizados que os indivíduos possuem acerca de si mesmo, das pessoas e do mundo. Todavia, o conceito de esquemas de Young é mais amplo, por incluir emoções, sensações corporais, memórias (YOUNG; KLOSKO; WEISHAR, 2008).

Nesse contexto, os esquemas desadaptativos podem ser entendidos como "padrões emocionais e cognitivos autoderrotistas iniciados em nosso desenvolvimento desde cedo e repetidos ao longo da vida." (YOUNG; KLOSKO; WEISHAR, 2008, p. 22). Eles são gerados na infância como forma de adaptação do indivíduo às necessidades emocionais não atendidas, e são perpetuados como verdades durante a vida adulta. Esses padrões estão ligados ao desenvolvimento de diversos transtornos mentais e, por essa razão, a terapia do esquema preconiza o trabalho com os pais, de forma a auxiliá-los a suprir habilmente as necessidades emocionais dos filhos, de forma a prevenir o desenvolvimento de EIDs, assim como quadros de psicopatologia na vida adulta (PAIM; ROSA, 2016).

É importante ressaltar que a teoria do apego, formulada por John Bowlby, contribuiu para a composição da terapia do esquema, uma vez que versa sobre a vinculação dos seres humanos. À vista disso, o desenvolvimento da criança está ligado ao relacionamento estabelecido com seu cuidador, se 
fazendo ressaltar que o "cuidado parental está relacionado não apenas ao desenvolvimento socioemocional da criança, mas também aos seus aspectos cognitivos." (HALPERIN; CARNEIRO, 2016, p. 33)

Halperin e Carneiro (2016) também indicam que Mary Ainsworth formalizou a teoria do apego, indicando três grandes categorias: apego seguro, apego inseguro/ansioso/ambivalente e apego inseguro evitativo. Main e Solomon incluíram ainda o apego desorganizado à essa lista. A compreensão dos tipos de apego pode ser entendida como a base familiar para o desenvolvimento dos EIDs, pois as vivências com a figura de apego formarão estruturas cognitivas que "irão encaminhar a representação que a criança terá de si mesma, dos outros e do mundo e, portanto, nortearão e darão forma a suas experiências e emoções ao longo da vida." (HALPERIN; CARNEIRO, 2016, p. 35). Assim, a importância da infância para o desenvolvimento de aspectos relacionados à saúde mental é novamente demonstrada.

Ainda cabe destacar as contribuições teóricas ligadas ao campo da cultura, no tocante ao exercício da parentalidade. Macarini et al. (2010) apontam que as crenças, valores e comportamentos possuem conotação cultural. Os autores afirmam que as compreensões culturais dos pais são organizadas em categorias de crenças, chamadas de etnoteorias parentais ou ainda sistemas culturais de crenças parentais. Tais sistemas agem como modelo para as práticas parentais. Dessa forma, depreende-se que o contexto cultural não pode ser negligenciado nessa discussão.

Diante do exposto, esta pesquisa teve como objetivo principal compreender o exercício da parentalidade a partir do entrelaçamento de algumas teorias, tais como terapia do esquema, teoria do apego e o estudo de etnoteorias parentais, e de que maneira tais compreensões teóricas podem auxiliar o exercício do papel parental para o desenvolvimento saudável da criança. Trata-se de uma pesquisa que serviu como requisito parcial para a aprovação na disciplina de Terapia Cognitivo-Comportamental do quarto ano do curso de Psicologia da Universidade da Região de Joinville (Univille).

\section{MÉTODO}

Trata-se de uma pesquisa qualitativa, na qual foram entrevistados seis pais e/ou mães na cidade de Joinville, estado de Santa Catarina, entre o período de 27 de julho de 2018 e 28 de setembro do mesmo ano. Para tanto, foi utilizado um roteiro de entrevista semiestruturada, com 10 perguntas préestabelecido pelo pesquisador responsável e orientador do presente estudo. Segundo Gonçalves et al. (2014, p. 38):

A entrevista semiestruturada ocorre quando as questões são anteriormente preparadas com um roteiro flexível que possibilite ganhar tempo e não repetir informações, mas que dá ao entrevistado a oportunidade de reflexão e revisão do que foi planejado. 
As entrevistas foram gravadas e ocorreram em locais adequados que preservaram o sigilo das informações. Posteriormente, foi realizada a transcrição delas. Os entrevistados concordaram em assinar o Termo de Consentimento Livre e Esclarecido e estavam cientes da gravação. Com o intuito de reconhecêlos pelas falas e preservar o sigilo, os participantes serão identificados com as siglas que iniciam em P1 e decorrem até P6.

A análise dos dados foi realizada de forma qualitativa, selecionando dados relevantes das falas dos entrevistados para associar com as teorias discutidas, de forma a assinalar e compreender tais práticas parentais à luz das teorias cognitivo-comportamentais, utilizadas como base referencial.

De acordo com Gonçalves et al. (2014), "A pesquisa qualitativa é útil para trabalhar com conceitos e fundamentos relevantes de determinadas situações". Ainda de acordo com os autores, a pesquisa qualitativa permite trabalhar questões difíceis de quantificar, como sentimentos, emoções, crenças e comportamentos dos indivíduos ou de uma coletividade, além de encontrar respaldo em teorias filosóficas (GONÇALVES et al., 2014).

É importante ressaltar que com relação a guarda dos documentos, o CFP institui na Resolução do $n^{\circ}$ 007/2003 que tais documentos são de responsabilidade total do psicólogo e devem ser guardados pelo prazo mínimo de 5 anos, sendo então destruídos após esse período (CFP, 2003).

\section{RESULTADOS E DISCUSSÃO}

Foram entrevistadas seis pessoas, sendo três homens e três mulheres, com faixa etária de 30 a 37 anos. Quanto à escolaridade, um dos participantes possuía ensino médio incompleto, dois possuíam ensino superior incompleto e três possuem ensino superior completo (um deles mestre e outro com duas formações distintas). No que diz respeito aos filhos dos entrevistados, suas idades variaram entre 8 (oito) meses à16 (dezesseis) anos de idade. Um dado importante a ser destacado é que dentre os participantes, quatro deles possuem apenas um(a) filho(a) e os outros dois, possuem dois filhos.

As duas primeiras perguntas realizadas durante a entrevista diziam respeito às necessidades das crianças e adolescentes e as dificuldades enfrentadas pelos pais para suprí-las. Neste sentido, em relação às necessidades, a teoria do apego explica que a forma como um indivíduo irá se relacionar com os outros durante a vida adulta está diretamente relacionada com a forma que foi cuidado em sua primeira infância, assim como com o suprimento de suas necessidades básicas e de afeto. De acordo com Ramires e Schneider (2010), a teoria do apego compreende que a formação e manutenção dos vínculos afetivos sustentam-se na necessidade de satisfazer certos impulsos, como a alimentação na infância e o sexo na vida adulta, entretanto, há nos bebês uma necessidade inata de contato com o ser humano que implica na necessidade de algo que vai além do alimento. Esse entendimento pode propiciar que os pais 
da atualidade apresentem uma nova forma de criar os filhos, de maneira muito mais afetiva do que foram criados.

Dalbem e Dell'aglio (2005), explicam que o modelo de apego desenvolvido durante a primeira infância é profundamente influenciado pela maneira como os cuidadores tratam o indivíduo. Ou seja, um indivíduo bem cuidado e que tenha suas necessidades supridas tende a se relacionar de uma forma mais saudável, assim como quando não o for, tende a ter relacionamentos não saudáveis. As referidas autoras explicam como a teoria do apego funciona:

[...]TA contempla os processos normais de desenvolvimento e a psicopatologia humana, além de abordar os processos de informação para a compreensão dos mecanismos psicológicos utilizados na vivência de um trauma ou uma perda, ou, ainda, na experiência de negligência ou rejeição pelas figuras de apego. Assim, essa abordagem teórica oferece uma base para estudos sobre os afetos e as emoções dos seres humanos, proporcionando um suporte empírico coerente para a compreensão dos processos de desenvolvimento normal e patológico, ao integrar aspectos da biologia moderna ao embasamento de seus estudos (DALBEM; DELL'AGLIO, 2005, p. 14).

Em relação às necessidades dos filhos, os pais entrevistados foram questionados se "Em sua opinião, quais as coisas que uma criança/adolescente mais precisa Analisando"? Avaliando as respostas obtidas pelos vieses da teoria do apego, é possível concluir que todos os pais, sem exceção, reconhecem a importância de um apego seguro. De acordo com Dalbem e Dell'aglio (2005), esse tipo de apego é caracterizado por ser um relacionamento cuidador-criança provido de uma base segura, na qual a criança pode explorar seu ambiente e que quando estressadas, as crianças buscam cuidado e proteção das figuras de apego - podem se sentir incomodadas quando separadas de seus cuidadores, mas não se abatem de forma exagerada por serem mais confiantes. Eis o que o participante 1 fala sobre as necessidades da criança: "O que uma criança mais precisa dos pais é a presença, em combinação com atenção e com afeto. A criança precisa se sentir segura mediante presença dos pais, juntos, em harmonia, com felicidade." (P1)

É possível observar nessa resposta exatamente o que se diz na teoria do apego: a importância do papel dos pais no desenvolvimento de uma criança. De uma forma geral, todos os pais entrevistados responderam que o que as crianças mais precisam é atenção e afeto dos pais. É possível refletir até que ponto os comportamentos dos pais são coerentes com os discursos e pensamentos. Ramires e Schneider (2010) afirmam que a existência do apego seguro possibilita ao indivíduo manter uma proximidade em relação à figura de apego, tornando-se um indivíduo identificado e dessa forma mais apto para lidar com o mundo. 
A segunda pergunta realizada foi: "Quais são as maiores dificuldades encontradas para oferecer as coisas que você pensa que são importantes para os filhos"? Nesta pergunta, houveram respostas diferentes entre si. No entanto, estas podem ser divididas em três categorias distintas. Dois dos entrevistados responderam que as maiores dificuldades enfrentadas são em relação ao tempo e "correria" (Sic) do dia a dia, entre outros aspectos socioeconômicos e culturais; um entrevistado respondeu que sua maior dificuldade é em relação a situação financeira e, por fim, os outros três responderam que suas maiores dificuldades são referentes às orientações e a forma de educar seus filhos, referindo ser difícil saber qual o momento de orientá-los e como o fazer, uma vez que há um conflito de valores ao que é transmitido em casa e ao que os filhos veem na rua.

As respostas dessa pergunta podem ainda ser analisadas através do viés da etnoteoria parental, a qual, segundo Macarini et al. (2010), pode ser caracterizada como um conjunto organizado de ideias que estão implícitas na atividade cotidiana. É possível observar que cada um dos entrevistados respondeu a segunda pergunta de acordo com a sua realidade cotidiana. Os referidos autores afirmam que há três modelos culturais de self distintos e através dessa percepção é possível categorizar os pais entrevistados no modelo 3. Este modele é denominado de autônomo-relacional, possuindo características dos outros dois modelos.

[...] englobando autonomia e relação no mesmo modelo, em que o self é definido como autônomo quanto a sua ação relacional quanto à proximidade interpessoal. Ele é característico de famílias de classe média, urbana e escolarizada em sociedades tradicionalmente independentes (MACARINI et al. 2010, p. 38).

Ainda em relação a forma de educar, a participante 4 (mãe de uma menina de 16 anos) respondeu que a maior dificuldade é de como dialogar com a filha.

A maior dificuldade é que alguns pais querem apenas impor suas vontades sem dar ouvidos aos filhos, gerando assim conflitos. Os pais precisam mostrar aos filhos seus desejos de forma clara através de diálogo de da atenção, que é o que mais falta (P4).

É possível observar nessa resposta a importância de um apego seguro, mesmo na adolescência. O quão importante é a forma de se comunicar com os filhos e principalmente de saber ouvi-los. Ramires e Schneider (2010, p.27) falam sobre a importância do diálogo para o vínculo seguro: "À medida que se engajam em diálogos verbais sobre os modelos funcionais, os pais servem como base segura para a exploração do mundo interno das suas crianças, para além da exploração do mundo externo". Ou seja, quando as crianças possuem 
uma relação de diálogo com os pais conseguem explorar a si mesmos de uma forma mais confiante de modo que se tornarão adultos mais saudáveis.

As autoras Dalbem e Dell'aglio (2005), compartilham da mesma opinião afirmando que adolescentes com padrão de apego seguro são mais confiantes em seus relacionamentos e em relação a si mesmos. Ainda segundo as autoras, esses adolescentes são considerados mais estáveis em suas relações românticas e suas relações com as figuras de apego são marcadas por uma interação de confiança.

Apesar de o diálogo ser muito relevante na criação de uma criança, a teoria do apego ressalta ainda a importância de se impor limites, uma vez que crianças ainda não possuem uma percepção de certo ou errado, cabendo aos pais estipularem regras. Ramires e Schneider (2010), afirmam que a formação do indivíduo se inicia durante o primeiro ano de vida e tais modelos provêm regras para a direção do comportamento, avaliação da experiência, organização da atenção e da memória e essas podem permitir ou limitar o acesso do indivíduo a certas formas de conhecimento a respeito de si mesmo.

As duas questões posteriores na entrevista tinham como intuito investigar os modelos culturais compartilhados de parentalidade dos participantes e os fatores que estes acreditam influenciar para o mal comportamento de seus filhos em algumas situações, respectivamente. Neste sentido, a teoria do apego diz que cada indivíduo forma - a partir das experiências com figuras de apego - seus modelos internos, sugerindo que tais experiências são internalizadas como representações dos indivíduos sendo carregadas e ampliadas durante suas vidas, as utilizando como base para outras relações.

Embora essas representações tenham sua origem cedo no desenvolvimento, elas continuam em uma lenta evolução, sob o domínio sutil das experiências relacionadas ao apego da infância. A imagem interna, instaurada com os cuidadores primários, é considerada a base para todos os relacionamentos íntimos futuros (DALBEM; DELL'AGLIO 2005, p. 14).

Os indivíduos ao longo de seu desenvolvimento estabelecem, segundo Bowlby (1989 apud Dalbem e Dell'aglio 2005), um modelo interno de funcionamento que se refere às representações das experiências da infância relacionadas às percepções do ambiente, de si mesmas e das figuras de apego. Esse modelo de funcionamento posteriormente é generalizado nas experiências sobre si mesmo, sobre os outros e sobre mundo.

Com relação aos modelos culturais compartilhados de parentalidade dos participantes a terceira pergunta realizada foi: "Você tem algum modelo que segue para educar/ensinar seu filho? Por exemplo, segue o modelo dos pais (avós da criança); leituras; prática pedagógica etc.". Nesta pergunta todos os participantes, sem exceção, responderam que os modelos seguidos para 
educar seus filhos foram seus pais e/ou mães. Em combinação ao modelo dos pais, alguns acrescentaram outras formas que têm seguido: três participantes disseram que fazem suas adequações ao modelo de seus pais, por seus valores não irem de encontro com algumas práticas e por acrescentarem práticas apreendidas em suas experiências de vida; um dos participantes entrevistados citou a literatura como modelo; e outro referiu práticas pedagógicas, como parte do modelo seguido. Analisando as respostas dos entrevistados acerca de seus modelos parentais, podemos verificar que todas são provenientes de suas vivências com seus cuidadores e tem relação aos seus contextos culturais, ou ainda, segundo Macarini et al. (2010), possuem concepções comuns acerca das etnoteorias parentais, de acordo com o contexto cultural em que estão inseridos.

A quarta pergunta realizada foi: "Em sua opinião, quais são os fatores que levam as crianças/adolescentes a se comportarem mal em algumas situações"? Grande parte dos entrevistados respondeu que o principal fator do mau comportamento está relacionado aos limites dados aos filhos, onde a falta de limites ou o excesso deles teria relação direta com comportamentos incongruentes de seus filhos, sendo prejudicial a eles. Analisando estas respostas a luz da terapia dos esquemas, Young, Klosko e Weishar (2008, p. 29) dizem que a deficiência em limites internos, responsabilidade para com outros indivíduos ou orientação para objetivos de longo prazo, leva a dificuldades de respeitar os direitos alheios, cooperar com outros, estabelecer compromissos ou definir e cumprir objetivos pessoais realistas. Esses mesmos autores ainda citam que tais dificuldades têm origem familiar típica e caracterizamse por permissividade, excesso de tolerância, falta de orientação ou sensação de superioridade, em lugar de confrontação, disciplina e limites adequados. Um dos entrevistados mencionou que o principal fator seria relacional, dado pelas influências relacionais externas com outras pessoas as quais os filhos se relacionam, ao passo que outro entrevistado referiu a falta de atenção dada aos filhos como principal fator do mau comportamento

Em relação às necessidades emocionais, Paim e Rosa (2016), defendem que para teoria do esquema (TE), há um ponto importante a ser tratado antes de entendê-la. Buscam primeiro compreender como se dá a estruturação da personalidade. Para eles, ela é vista como um processo natural, originando das bases genéticas herdadas. Estas mesmas definem o temperamento de um indivíduo. $\mathrm{O}$ temperamento resultará nas tendências comportamentais, afetivas, cognitivas e motivacionais do mesmo, juntamente com as experiências vividas por aquele sujeito.

Lockwood \& Perris (2012 apud Wainer, 2016), definem que o temperamento é considerado um determinante biológico da personalidade e não pode ser modificado em sua totalidade ainda que por influências ambientais. Tratando-se de temperamento, este é um ponto importante para se entender as necessidades emocionais, visto que por meio dele é definida a quantidade ideal que cada sujeito demanda para suprir tais necessidades: 
Portanto, dependendo de seu temperamento, uma pessoa pode, por exemplo, requerer mais demonstrações de afeto de seus cuidadores no início da vida que seu irmão, o qual, de forma inversa, pode necessitar de maior quantidade de limites afetivos em uma fase mais posterior (PAIM; ROSA, 2016, p. 15).

No que concerne à questão citada anteriormente, um dos participantes da entrevista, pai de um filho 15 e outro de 2 anos de idade, ao ser questionado sobre seu conhecimento e como percebe as necessidades emocionais de seus filhos, expressou-se da seguinte maneira:

Eu li, em teoria sei bastante assim, tenho bastante conhecimento nesse assunto. É... o mais velho assim, ele é bem, como é que eu vou dizer, bem... ah precisa toda hora que o cara esteja junto assim bem apegado. Apesar de não morar comigo, mesmo assim, quase...A gente se vê direto assim. Eu separei da mãe dele quando ele era bem pequeninho, mas nunca fiquei longe (P2).

Essa fala abre margem para discutir a importância do papel dos pais. De acordo com Bowlby (1973/1984 apud Dalbem e Dell'Aglio, 2005), o relacionamento da criança com os pais é instaurado por um conjunto de sinais inatos do bebê, que demandam proximidade. Conforme a criança se desenvolve, constrói-se um verdadeiro vínculo afetivo e este é garantido pelas capacidades cognitivas e emocionais da criança, bem como pelo cuidado constante, pela sensibilidade e responsividade dos seus cuidadores. Ainda quanto às necessidades dos filhos, um participante mencionou, inclusive, basear-se em estudos:

Acredito que algumas necessidades emocionais são: impor limites, ensinar a respeitar o próximo, passar segurança. carinho, proteção... procurar fazer pesquisa a cada idade que ela completa (P6).

O participante 3 relatou que ao observar que sua filha está sentindo alguma emoção: "Tento conversar e explicar sobre essa emoção, sempre dando a informação necessária de que são emoções, que podem voltar e que precisam ser tratadas."

Segundo H. Waters, C. Hamilton \& N. Weinfield (2000 apud Dalbem e Dell'Aglio, 2005) as representações sensório-motoras que um indivíduo irá obter a partir das suas experiências é que darão origem às suas representações mentais, fortalecendo e desenvolvendo assim, uma base segura da infância. Conforme as representações se desenvolvem, estas serão construídas cada vez mais com maior complexidade. Ainda assim, não se pode deixar de levar em conta a idade e o desenvolvimento cognitivo deste sujeito.

Quando se trata das necessidades emocionais básicas de um indivíduo, é importante ressaltar que os cuidadores possuem participação imprescindível 
nesse aspecto. De acordo com Paim e Rosa (2016), quanto mais cuidados amorosos dos pais as crianças receberem e mais saudável for o ambiente o qual está inserido, melhores serão as habilidades de conexão e autocuidado que esse sujeito irá possuir ao enfrentar estresses na vida adulta.

Um dos participantes, quando questionado sobre como lida com as emoções da filha afirmou que:

Costumeiramente eu lido da forma mais pacífica possível né. Se ela tá feliz eu tô feliz junto, se ela fica com medo eu tento acolher. Quando ela tá com raiva, aí depende da situação né, às vezes a gente tenta explicar, porque às vezes foi a gente que causou, ou uma situação desagradável, ou às vezes não é nada, mas ela não compreende né, que não é nada. Então a gente tenta amparar de forma a trazer o melhor resultado (P1).

Desta forma, o papel da família é imprescindível na formação da personalidade da criança e na sua capacidade de desenvolver altos níveis de resiliência para lidar com as dificuldades que aparecerão no decorrer da sua vida (WAINER, 2016). Assim, para que haja uma "base segura" e estabilidade emocional na vida deste indivíduo, é necessário que os responsáveis por ele sejam presentes em relação a doses de apego, carinho, segurança, conforto emocional e capacidade de acalmar as ansiedades e impulsividades (PAIM; ROSA, 2016, p.16). A resposta de um dos entrevistados ilustra:

Eu procuro entender o motivo que veio sentir essa emoção: tristeza por exemplo, por ter 8 meses: quando chora, atendo com suas necessidades básicas. Por exemplo, dou água, troco as fraldas, brinco, auxílio para dormir, dou banho... Quando sente raiva: mesmo sem idade suficiente para entender, converso para não sentir raiva. E quando sente medo eu tento proteger, mas em algumas situações deve encarar o medo, mas com minha supervisão. Quando sente nojo ainda não fica notável. Quando ela sente alegria eu incentivo a ter mais momentos alegres, se ela fica feliz com alguma coisa, ou brinquedo procuro repetir o que a fez deixar alegre (P6).

Por outro lado, crianças negligenciadas podem desenvolver tipos de estresse precoces. Em relação às negligências, Petersen e Wainer (2011 apud Paim e Rosa, 2016), listam aquelas referentes às necessidades básicas como alimentação, higiene, moradia além de proteção, afeto e empatia. Esta última, por muitos considerada secundária ou mesmo supérflua, tem demonstrado possuir influências significativas com relação a quadros psicopatológicos severos nos sujeitos.

Segundo Martins et al. (2011, apud Paim e Rosa, 2016) o estresse precoce, seja na forma de negligência, de violência ou déficits nos cuidados e necessidades básicas, desencadeiam sequelas psicológicas e ampliam expressivamente as 
chances de os jovens desenvolverem comportamentos psicopatológicos na vida adulta.

A sétima pergunta realizada foi a seguinte: "O quanto você incentiva seu filho a tomar pequenas decisões e ser independente de acordo com a idade dele"? As respostas, de modo geral, demonstraram atitudes de incentivo à independência dos filhos conforme a idade, como podemos notar na resposta do participante 1, que tem uma filha de um ano e oito meses: "Olha incentivo um bocado, costumeiramente com opções pra comida assim né, frutas ou iogurte assim que ela queira, e às vezes com brinquedos: eu pergunto com qual ela quer brincar, onde tá, pra ela buscar" (P1).

Com base na Terapia do Esquema, como já citado anteriormente, os cuidadores têm papel muito significativo no desenvolvimento das capacidades de resiliência, para lidar com os desafios da vida. Pode-se considerar que o incentivo à autonomia na tomada de decisão e à independência, de acordo com sua idade, é um aspecto importante para o desenvolvimento saudável do indivíduo frente às demandas da vida.

Wainer (2016) afirma que:

A TE assume um modelo compreensivo, empiricamente embasado, sobre as necessidades emocionais básicas dos seres humanos [...]. Ela demonstra que, durante a infância e adolescência, o ser humano tem seis necessidades centrais organizada em pares: conexãoautonomia, estabilidade-mudança e desejabilidade-autoaceitação (LOCKWOOD; PERRIS, 2012 apud WAINER, 2016).

Considerando o primeiro par de necessidades centrais citado acima, conexão-autonomia, os pais entrevistados parecem contemplar satisfatoriamente essas necessidades na relação com seus filhos. A participante 3 respondeu da seguinte forma:

Sempre tive medo de tudo que está em volta da minha filha, procurando fazer tudo por ela. Mas com o passar dos anos a gente percebe que devemos deixar eles tomarem suas próprias decisões para se prepararem para o dia a dia. Então hoje procuro sempre fazer isso, deixá-la fazer as coisas. Mas ainda tenho alguns medos (P3).

Nesse relato, torna-se nítido o que a Terapia do Esquema entende quanto à estruturação da personalidade:

A estruturação da personalidade é vista como um processo natural e que tem suas fundações nas bases genéticas herdadas, as quais definem o temperamento e, assim, as tendências comportamentais, afetivas, cognitivas e motivacionais que sofreram os efeitos do ambiente por meio das aprendizagens constantes no transcorrer do ciclo vital (WAINER, 2016). 
A Teoria do Apego também pode ser utilizada para auxiliar na interpretação dos dados obtidos na pesquisa. De acordo com essa teoria,

[...] bebês precisam estabelecer um relacionamento com seu cuidador para que possam se desenvolver. Esse desejo de proximidade expressado pela criança é chamado de apego, e inicialmente exprime as necessidades de segurança e proteção do recém-nascido. Essas duas irão constituir os pilares da saúde mental do infante, pois a forma como os pais desenvolvem esse vínculo inicial está diretamente associada aos padrões de apego que a criança irá desenvolver (RAMIRES; SCHNEIDER, 2010 apud HALPERIN; CARNEIRO, 2016).

A Terapia do Esquema é uma das teorias que se baseiam na Teoria do Apego. Para facilitar a compreensão subjetiva e emocional, os 18 Esquemas Iniciais Desadaptativos foram agrupados em cinco categorias de necessidades emocionais não atendidas, chamadas de domínios esquemáticos (HALPERIN; CARNEIRO, 2016). Dentre os cinco domínios, destaca-se nessa questão o segundo, no qual o prejuízo na autonomia e desempenho afeta a possibilidade de viver-se de maneira independente. Os EIDs presentes nesse caso são: dependência/incompetência, vulnerabilidade ao dano ou à doença, emaranhamento e fracasso (HALPERIN; CARNEIRO, 2016).

A oitava questão investigou a opinião dos pais com relação aos limites aos filhos. As respostas expressaram, de um modo geral, a necessidade de se impor limites. Nas respostas também surgiram questões como as dificuldades encontradas para exercer limites e a necessidade do limite perante a realidade social. Quanto às dificuldades podemos destacar a resposta do participante 1:

Olha, tá aí uma questão deveras periquitante, devido ao fato de que às vezes as crianças não ficam sob supervisão de um único adulto, então as ideias podem divergir, e isso vai ocasionar numa série de problemas futuros, né. Eu acho que devem existir limites sim, mas só quem é pai sabe a dor que é ver o seu filho chorando, e como a gente não quer que isso aconteça, sabe, então às vezes os próprios pais extrapolam os limites que eles gostariam que existissem pra evitar ver o choro do filho sabe. Portanto, limites devem existir sim, mas você tem que ser maleável, você tem que ser apaixonado pelo seu filho, pra fazer funcionar de uma maneira feliz para o desenvolvimento da criança, menos traumática possível (P1).

Neste relato, pode-se notar o que Harkness e Super (1996) trazem em relação as etnoteorias parentais: "As crenças parentais sobre práticas de cuidado caracterizam-se pelo conjunto de ideias que estão implícitos na atividade cotidiana e nos julgamentos, escolhas e decisões que os cuidadores tomam em relação a seus filhos" (HARKNESS; SUPER, 1996 apud MACARINI et al., 2010). 
Na resposta do participante 4, vê-se explícita a preocupação com a questão social:

Os limites têm que ser impostos sim. Pois crianças sem limites são crianças sem controle e não vão querer ouvir "NÃ̂O" como resposta. Os limites ensinam sobre o certo e o errado e que vivemos em uma sociedade com direitos e deveres que devem ser respeitados (P4).

Essa preocupação com o social também tem relação com a forma como os pais foram criados culturalmente e as mudanças que eles julgam necessárias ser aplicadas na educação de seus sucessores. "O que mães e pais pensam e como eles agem em relação aos filhos têm forte conotação cultural e, por conseqüência, contextual. Nesse sentido, as crenças podem ser consideradas como resultado de um processo social/cultural e individual [...]" (HARKNESS; SUPER, 1996; HARKNESS; SUPER; VANNA AXIA; PALACIOS; WELLESNYSTRÖM, 2001 apud MACARINI et al., 2010).

Relacionando com a Teoria do Apego, destaca-se aqui o terceiro domínio, no qual o prejuízo nos limites decorre em problemas na compreensão dos direitos das pessoas, no respeito desses direitos e no compromisso em respeitá-los. Os EIDs relativos à esse domínio são: arrogo/grandiosidade e autocontrole/indisciplina insuficientes (HALPERIN; CARNEIRO, 2016).

Para a terapia do esquema, caso a necessidade de liberdade de expressão e validação de necessidades e emoções não seja suprida, esquemas desadaptativos relativos ao direcionamento para o outro podem surgir. São eles: subjugação, auto sacrifício e busca de aprovação/ busca de reconhecimento (YOUNG; KLOSKO; WEISHAR, 2008). Tais autores explicam que os indivíduos nesse domínio de esquema focalizam em demasia as necessidades alheias, em detrimentos das suas próprias necessidades.

De acordo com Yonung, Kosko e Whishar (2008), a origem familiar desses esquemas tem como ponto principal a aceitação condicional: as crianças não possuem liberdade quanto a suas predileções e são orientadas a restringir tais aspectos para obter amor da figura parental.

Por outro lado, pais que permitem à criança expressar seus desejos e sentimentos e ensinam a importância de considerar as necessidades alheia propiciam um equilíbrio e um ambiente supridor da necessidade de validação das necessidades e emoções (PAIM; ROSA, 2016).

Os dados obtidos por meio das entrevistas indicam o entendimento dos pais quanto a esses aspectos. Um participante expressou da seguinte maneira sua avaliação quanto a importância de as crianças seguirem suas inclinações e expressarem suas emoções:

Ah, eu acho que desde criança até adolescente tem que ter atitude própria né, não pode só querer... tem que ser independente né, 
não pode só querer fazer o que os outros querem né, tem que ter o próprio gosto, tem que debater né, se ele gosta de uma coisa tem que seguir a linha dele. Tem criança que não vai né, faz uma coisa até que não gosta pra agradar o outro né, aí não pode né tem que ter atitude própria, tem que ter atitude (P2).

Dessa maneira, é possível perceber que o entrevistado em questão compreende que não "seguir sua linha" pode levar uma pessoa a agir "pra agradar o outro". Outro participante expõe sua opinião da seguinte forma:

Nossa, eu sou totalmente a favor assim, eu sou um cara que gosta muito de se expressar, e porque não o deixaria minha filha fazer? Então, eu sou doido pra ver o que mais ela pode trazer pra gente de novidade assim e alegrar nossos dias, sou totalmente a favor (P1).

Essa fala aponta para uma questão importante, tratada por Paim e Rosa (2016): os esquemas parentais, adaptativos ou desadaptativos, podem contribuir para a efetivação de um ambiente supridor ou privativo, respectivamente. Assim, em alguns casos é importante que os pais realizem terapia individual para o desenvolvimento saudável da criança.

São exemplos de atitudes parentais reparadoras, quanto à liberdade de expressão e validação de necessidades e emoções:

Estimular a liberdade em realizar espontaneamente os seus próprios desejos, fazendo a criança entender que precisa haver um equilíbrio entre suas necessidades e as dos outros. Não condicionar o amor e aceitação a passividade e submissão. Preservar a criança do envolvimento excessivo em problemas familiares (PAIM; ROSA, 2016, p. 152).

É importante buscar um equilíbrio em relação às necessidades das crianças e as necessidades alheias, sejam dos pais, ou até mesmo exigências sociais. Nesse sentido, um realizou a seguinte reflexão:

Eles vão sempre expressar suas emoções, sejam boas ou ruins. O papel do pai educador é filtrar essas emoções e ensinar o que cada comportamento pode gerar e suas consequências. Eles têm direito de escolha sim, mas nada que possa denegrir o seu aprendizado como cidadão que estamos criando para o mundo (P4).

Nesse contexto, quando falamos sobre esquemas de direcionamento para outro, é importante ressaltar que muitas vezes os pais reforçam a supressão de inclinações da criança tendo em vista a questão da aparência (YOUNG; KLOSKO; WEISHAR, 2008). A aparência pode englobar questões como ser um bom cidadão, trabalhador, ou outras exigências, de acordo com questões de valores e crenças parentais. À vista disso, é sempre importante considerar 
o contexto cultural dos pais para entender a incidência desse contexto na motivação do estímulo ou supressão de determinados comportamentos.

A terapia do esquema (YOUNG; KLOSKO; WEISHAR, 2008) postula ainda que, ao não ser satisfeita a necessidade de espontaneidade e lazer, tornase provável a emergência de esquemas desadaptativos de supervigilância e inibição, tais quais: negativismo/pessimismo, inibição emocional, padrões inflexíveis/postura crítica exagerada e postura punitiva.

De forma semelhante ao que ocorre no domínio tratado anteriormente, o indivíduo suprime seus sentimentos e impulsos, buscando seguir rígidas regras internalizadas, em detrimento da sua espontaneidade, relaxamento, entre outros aspectos para uma condição de vida saudável.

De acordo com Young, Klosko e Wheishar (2008, p. 33): "quando crianças, esses pacientes não foram estimulados a ter momentos de lazer e a buscar a felicidade, e sim a estar supervigilantes em relação a eventos negativos na vida e a considerá-la triste.".

Por outro lado, um ambiente supridor possibilita que a criança expresse espontaneamente suas necessidades e emoções interessando-se de forma empática e genuína. Paim e Rosa (2016, p. 152) oferecem exemplos de atitudes parentais reparadoras quanto a espontaneidade e lazer: "ter momentos familiares felizes e de lazer, mostrando a ela que não é errado se divertir e ser espontâneo. Brincar com o filho, servindo como modelo de diversão e espontaneidade. Demonstrar sentimentos e emoções".

Todos os pais entrevistados avaliam como necessários os momentos de brincadeira e lazer das crianças. Muitos relacionaram essas práticas ao desenvolvimento saudável dos filhos:

Olha: uma criança que tem os seus momentos de descontração, de lazer assim, integração com outras crianças, ela vai se desenvolver de uma forma muito mais alegre, muito mais sadia, vai aprender a lidar com situações de desavença, de amizade, tudo, tudo, tudo, você vai conseguir explorar muito mais as várias áreas que uma criança pode desenvolver (P1).

Ou ainda, como expõe outro entrevistado:

A criança tem que brincar, tem que ter menas responsabilidade e mais brincadeira, tem que sempre ta se movimentando, até porque quando tá brincando, tá com saúde né, tem que brincar (P2).

O participante 2 também lembrou sobre o advento da tecnologia: "Nós, como pais, temos sempre que estimular essas brincadeiras e estar presente mostrando a eles o quão bom é brincar e deixar um pouco a vida de celular de lado.". Nesse contexto, é possível perceber mais uma vez, que o contexto cultural afeta as 
práticas parentais. Acreditamos que o uso de tecnologias por crianças e sua relação com a estruturação da personalidade deve ser melhor explorado em outra produção, todavia, pontuamos que os aspectos cognitivos e culturais precisam ser incluídos nessa reflexão.

Conforme discutimos anteriormente, os esquemas e as experiências parentais influenciam no manejo dos pais com seus filhos. Ao tratar da relevância da brincadeira para a criança, o participante $5 \mathrm{faz}$ a seguinte ponderação:

[...] a criança tem que viver né, eu vivi bastante, não sei tu né, mas eu vivi bastante. Eu vivi numa chácara, então eu pude aproveitar um monte, comer frutas subir em árvores, essas coisas. Então isso que é importante: eu vivenciei isso daí, esse momento de brincar, tinha momento de responsabilidade, mas a maioria das vezes era o dia todo na rua, ia pra almoçar, depois já voltava pra rua só a noite, então não tinha. Hoje já é um pouco mais perigoso de tu fazer isso, na rua lá onde eu moro passa bastante carros, então não tem como eu deixar, aí quando dá a gente dá só um tempo a gente vai lá na casa dos meus pais que é um terrenão grande, aí larga eles, ou vamo lá na Embraco brincar, eles somem, vão brincar. Mas é isso, é muito importante a criança vivenciar e tu como pai, eu como pai, tem que proporcionar né, tem que dar esse mundo pra eles, abrir esse leque pra eles "Ó filho vai brincar, se vira aí, inventa [...]" (P5).

Esse trecho é ilustrativo também quanto ao incentivo e participação dos pais, necessários no que tange ao lazer. Todavia, é importante lembrar que a questão do tempo está entre as principais queixas elencadas pelos entrevistados quanto as dificuldades existentes para proporcionar o que julgam importante para a criança. Além disso, o entrevistado cita a questão da violência. Assim como exposto ao falar sobre a tecnologia, consideramos um tema de complexidade no que se refere à estruturação da personalidade, sendo necessário o desenvolvimento de um estudo à parte para essa questão.

Por fim, é válido ressaltar que, assim como outras necessidades, a procura por um ambiente equilibrado é fundamental. Um dos participantes se deteve à essa questão:

Toda criança precisa de momentos de lazer, brincar, faz com que ela acompanhe sua idade com um crescimento saudável, porém precisa ter compromisso, como por exemplo: fazer as tarefas escolares antes de brincar, comer em horários apropriados, ou seja, ter uma rotina onde seus pais possam acompanhar (P6).

Young, Klosko e Weishar (2008, p. 32), lembram de possíveis origens dos esquemas desadaptativos relacionados aos limites prejudicados do indivíduo: "quando crianças, não lhes foi exigido que seguissem as regras aplicadas a todas as outras pessoas, que considerassem os demais ou que desenvolvessem 
autocontrole.". Nesse sentido, entender que a criança precisa de espaço para brincadeiras e espontaneidade não é o mesmo que possuir práticas parentais permissivas ou indulgentes.

\section{CONSIDERAÇÕES FINAIS}

O trabalho teve como objetivo principal compreender o exercício da parentalidade sob a luz de teorias como a terapia do esquema, teoria do apego e estudos de etnoteorias parentais. Além disso, buscamos entender de que maneira essas compreensões poderiam auxiliar no exercício parental, buscando o desenvolvimento saudável da criança.

As informações obtidas por meio das entrevistas com os pais permitiram que fosse possível compreender como suas práticas estão ligadas ao desenvolvimento saudável da criança. A parentalidade é exercida sob influência da estruturação de personalidade das figuras parentais - esquemas, apegos - assim como, de acordo com o contexto cultural que a família se encontra inserida. Nesse sentido, verificamos que a terapia do esquema pode auxiliar no desenvolvimento saudável da criança, ao identificar ambientes que não suprem suas necessidades e auxiliar as figuras parentais nesse empreendimento, sendo importante considerar o meio que a família está inserida.

Diante do exposto, sugerimos que observações sejam incluídas nos próximos estudos, a fim de enriquecer a compreensão das práticas parentais. Também destacamos a importância do advento da tecnologia e de contextos socioculturais de violência serem estudados, no que concerne à estruturação da personalidade da criança, levando em conta o entrelaçamento de teorias culturais e psicológicas - visto serem assuntos de grande complexidade.

\section{REFERÊNCIAS}

CONSELHO FEDERAL DE PSICOLOGIA. Como devo fazer guarda e descarte de documentos utilizados no atendimento, 2003. Disponível em: <https:/ / site. cfp.org.br/faq/como-devo-fazer-guarda-e-descarte-de-documentos-utilizados-noatendimento/>

DALBEM, Juliana Xavier; DELL'AGLIO, Débora Dalbosco. Teoria do Apego: Bases conceituais e desenvolvimento dos modelos internos de funcionamento. Arquivos Brasileiros de Psicologia. UFRGS. 2005. Vol.57, n.1. P. 12-24.

GONÇALVES, Mônica Lopes et al. Fazendo Pesquisa: Do projeto à comunicação científica. 4. ed. Joinville: Univille, 2014. 120 p.

HALPERIN, Carolina Fischmann; CARNEIRO, Júlio César Rodrigues. A teoria do apego e as bases familiares da terapia do esquema. In: WAINER, Ricardo et al. (Org.). Terapia Cognitiva Focada em Esquemas: Integração em Psicoterapia. Porto Alegre: Artmed, 2016. p. 33-40. 
KNAPP, Paulo et al. Terapia Cognitivo-Comportamental na Prática Psiquiátrica. Porto Alegre: Artmed, 2004.

MACARINI, Samira Mafioletti et al. Etnoteorias Parentais: Um Estudo com Mães Residentes no Interior e na Capital de Santa Catarina. Psicologia: Reflexão e Crítica, Porto Alegre, v. 23, n 1, p. 37-45, abr. 2010. Disponível em: < http://www.redalyc. org/articulo.oa?id=18815254006 >. Acesso em: 30 set. 2018.

ORGANIZAÇÃO MUNDIAL DA SAÚDE. Aumenta o número de pessoas com depressão no mundo, 2017. Disponível em: < http:/ / www.paho.org/bra/index. php?option=com_content\&view=article\&id=5354:aumenta-o-numero-de-pessoascom-depressao-no-mundo\&Itemid=839>. Acesso em: 30 set. 2018.

PAIM, Kelly; ROSA, Martha. O papel preventivo da terapia do esquema na infância. In: WAINER, Ricardo et al. (Org.). Terapia Cognitiva Focada em Esquemas: Integração em Psicoterapia. Porto Alegre: Artmed, 2016. p. 149-167.

RAMIRES, Vera Regina Röhnelt; SCHNEIDER, Michele Scheffel.. Revisitando alguns Conceitos da Teoria do Apego: Comportamento versus Representação? Psicologia: Teoria e Pesquisa.Universidade do Vale do Rio dos Sinos (UNISINOS). 2010, Vol. 26 n. 1, P. 25-33.

WAINER, Ricardo. O desenvolvimento da personalidade e suas tarefas evolutivas. In: WAINER, Ricardo et al. (Org.). Terapia Cognitiva Focada em Esquemas: Integração em Psicoterapia. Porto Alegre: Artmed, 2016. p. 13-20.

YOUNG, Jeffrey E.; KLOSKO, Janet S.; WEISHAAR, Marjorie E. Terapia do Esquema: Guia de técnicas cognitivo-comportamentais inovadoras. Porto Alegre: Artmed, 2008. 